\title{
Freshwater sponge spicules: a new agent of ocular pathology
}

\author{
Cecilia Volkmer-Ribeiro/ ${ }^{+}$, Henrique L Lenzi*, Fernando Oréfice**, \\ Marcelo Pelajo-Machado*, Leandro M de Alencar, Carlos F Fonseca***, \\ Twiggy CA Batista****, Pedro PA Manso*, Janice Coelho*****, Marcelo Machado*****
}

Museu de Ciências Naturais, Fundação Zoobotânica do Rio Grande do Sul, Rua Dr. Salvador França 1427, 90690-000 Porto Alegre, RS, Brasil *Departamento de Patologia, Instituto Oswaldo Cruz-Fiocruz, Rio de Janeiro, RJ, Brasil **Departamento de Oftalmologia e Otorrinolaringologia, Universidade Federal de Minas Gerais, Belo Horizonte, MG, Brasil

***Hospital de Referência, Secretaria Estadual da Saúde, Augustinópolis, TO, Brasil ****Diretoria de Vigilância à Saúde, Secretaria Estadual da Saúde, Palmas, TO, Brasil *****Serviço de Anatomia Patológica, Instituto de Investigação Clínica, IPEC-Fiocruz, Rio de Janeiro, RJ, Brasil

In a recent outbreak of human ocular injuries that occurred in the town of Araguatins, at the right bank of Araguaia river, state of Tocantins, Brazil, along the low water period of 2005, two patients (8 and 12-year-old boys) presented inferior adherent leukoma in the left eye (OS), and peripherical uveites, with snowbanking in the inferior pars plana. The third one (13-year-old girl) showed posterior uveites in OS, also with snowbanking. Histopathological analysis of lensectomy material from the three patients and vitrectomy from the last one revealed several silicious spicules (gemmoscleres) of the freshwater sponges Drulia uruguayensis and D. ctenosclera. This work brings material evidences, for the first time in the literature, that freshwater sponge spicules may be a surprising new etiological agent of ocular pathology.

Key words: Drulia uruguayensis - Drulia ctenosclera - eye - ocular pathology - sponge spicules - foreign body

The recent outbreak of human ocular injuries, most of them in the conjunctive, occurred in the town of Araguatins, at the right bank of Araguaia river, state of Tocantins, Brazil, along the low water period of 2005. It affected particularly male children and adults and present, as main characteristic, immediate eye irritation and itching after bathing and diving with open eyes in the river waters. This outbreak reached more than 200 children and young people and was initially attributed to helminthic infection. Later on, a survey made by technicians of Ministry of Health showed that $80 \%$ of the children tested exhibited high levels of $\mathrm{IgG}$ antibodies to Toxocara canis (Report of Ministry of Health of October 18, 2006). However, the large number of registers of itching and skin ulceration caused by sponge spicules in the Amazonian Region, previously reported in the Zoological (Machado 1947), Archeological (Hilbert 1955), and Historical (Matta 1934, Brazil 1938) bibliography led Volkmer-Ribeiro and Batista to do a survey for sponges and its spicules in the water and sediments at several stations of Araguaia river. Indeed, an abundant fauna consisting of ten sponge species was detected and the presence of large number of spicules in the river water was noted (Volkmer-Ribeiro \& Batista, pers. commun.). These results were im-

Financial support: MCN/FZB, Fiocruz, CNPq, Ministério da Saúde, Universidade Federal de Minas Gerais, Secretaria da Saúde do Tocantins

${ }^{+}$Corresponding author: cvolkmer@fzb.rs.gov.br

Received 26 July 2006

Accepted 21 November 2006 mediately communicated to the scientific community engaged in the study under the Ministry of Health coordination, and a next step was carried out aiming to detect sponge spicules in surgically removed ocular lesions. This work focuses on the three first cases, where freshwater sponge spicules were clearly evidenced in intraocular lesions, defining, for the first time in the literature, a surprising new etiological agent of ocular pathology.

\section{MATERIALS AND METHODS}

Patients - Three young patients from the town of Araguatins, state of Tocantins, Brazil, with the habit of swimming in Araguaia river, came to the Reference Hospital of Augustinopolis, in the same state: a 12-yearold boy (SPF), a 13-year-old girl (GTA), and a 8-yearold boy (IVAA), all of them complaining of slow and progressive low vision for the past 4 to 6 months. They were first examined by three ophthalmologists, with bestcorrected visual acuity (BCVA), tonometry, biomicroscopy, and fundus examination. Afterwards, they underwent diagnostic and therapeutic surgical procedures such as cataract extraction with intra-ocular lens (IOL) implantation (three patients) and pars plana vitrectomy (one patient). The surgical procedures were performed in Hospital São Geraldo, Universidade Federal de Minas Gerais (UFMG), at Belo Horizonte city, capital of the state of Minas Gerais, Brazil.

Histotechnology processing - Lens cortex and vitreous specimens were fixed in $10 \%$ formalin. In Pathology laboratory each material was centrifuged in a conic tube (600 rpm for $10 \mathrm{~min}$ at room temperature), the supernatant was poured off, and cell block fixative was added for more than $3 \mathrm{~h}$ to allow protein to precipitate 
out (fixative: $99 \%$ ethanol - $85 \mathrm{ml} ; 10 \%$ formaldehyde $-10 \mathrm{ml}$; acetic acid $-5 \mathrm{ml}$ ). The result button of material was detached from the tube wall, enveloped in paper filter, and processed in routine Automated Processor. The material was embedded in paraffin and $5 \mu \mathrm{m}$ sections were stained with hematoxylin-eosin (HE), PAS, Sirius Red pH 10.2 (Bogomoletz 1980, Luque \& Montes 1989), Masson's trichrome, orcein, and Perls. The sections were analyzed by bright-field microscopy and confocal microscopy in reflected and transmitted light (LSM-510META, Zeiss).

Sponge spicules preparation - To prepare spicules clean of their organic matrix, fragments with gemmules of specimens from Drulia uruguayensis Bonetto \& Ezcurra de Drago 1968 and D. ctenosclera VolkmerRibeiro \& Mothes de Moraes 1981 obtained from the bottom of Araguaia river were boiled in pure nitric acid. The resulting spicular sediment was washed in tap water for acid removal and dropped on histological slides. After complete drying, coverslips were mounted on Entellan (Merk) over the sediment. The slides were analyzed by reflected and transmitted confocal microscopy, using the same procedures applied to the tissues.

\section{RESULTS}

Clinical aspects. Case 1 - A 12-year-old boy (SPF) that complained of slow and progressive low vision for the last 14 months. He was IgM negative and IgG positive to toxoplasmosis, IgG positive to toxocariasis, VDRL negative and presented peripheral eosinophilia. On July 14,2005 , ocular examination revealed a visual acuity of $20 / 20$ in the right eye (OD) and 20/100 in the left eye (OS) and intra-ocular pressure of $11 \mathrm{mmHg}$ in OD and 5 $\mathrm{mmHg}$ in OS. Biomicroscopy showed normal OD and inferior adherent leukoma in OS, with deep vascularization and dense cellularity in the anterior chamber $(4+/ 4+)$ (Fig. 1). Funduscopy was normal in OD and not possible in OS. He was treated with topical $1 \%$ prednisolone acetate $(\mathrm{q} 1 \mathrm{~h})$, in addition to oral prednisone (40 mg/day, with decrescent dosing). Sphincterectomy with $\mathrm{Nd}$ :YAG laser was performed to remove anterior synechia and clear visual axis. He presented an improvement in the visual acuity $(20 / 150)$ and later on developed cataract in OS. He then underwent uneventful cataract surgery with IOL implantation, with final BCVA of $\mathrm{OD}=20 / 20, \mathrm{OS}=20 / 200$. On March 2, 2006, fundus examination disclosed a normal posterior pole.

Case 2 - A 13-year-old girl (GTA) showed slow and progressive decrease in visual acuity that had begun four months ago. On July 7, 2005, BCVA was 20/20 in OD and $20 / 150$ in the OS. Intra-ocular pressure was 19 $\mathrm{mmHg}$ in OD and $28 \mathrm{mmHg}$ in OS. Biomicroscopy was normal in OD and showed mutton fat keratic precipitates in OS, with initial opacity in the crystalline lens and pigment clumping in the anterior capsule (Fig. 2). Fundus examination was normal in OD and showed vitreous haze in OS. A classical treatment to toxoplasmosis (with sulfadiazine, pyrimetamine, folinic acid, and prednisone) was initiated, even in the presence of negative serum antitoxoplasmosis IgM and IgG. Two weeks later, inferior snow banking and optic disc with irregular contour were observed. A fibrous stripe extending anteriorly from the optic disc was noted in OS. Progressive lens opacification occured, with worsening of visual acuity. On February 2006, she underwent scleral buckling, pars plana lensectomy and vitrectomy with IOL implantation in OS. On April 20, 2006, BCVA in OS was 20/50-2. Funduscopy revealed fibrous proliferation on the papillomacular bundle.
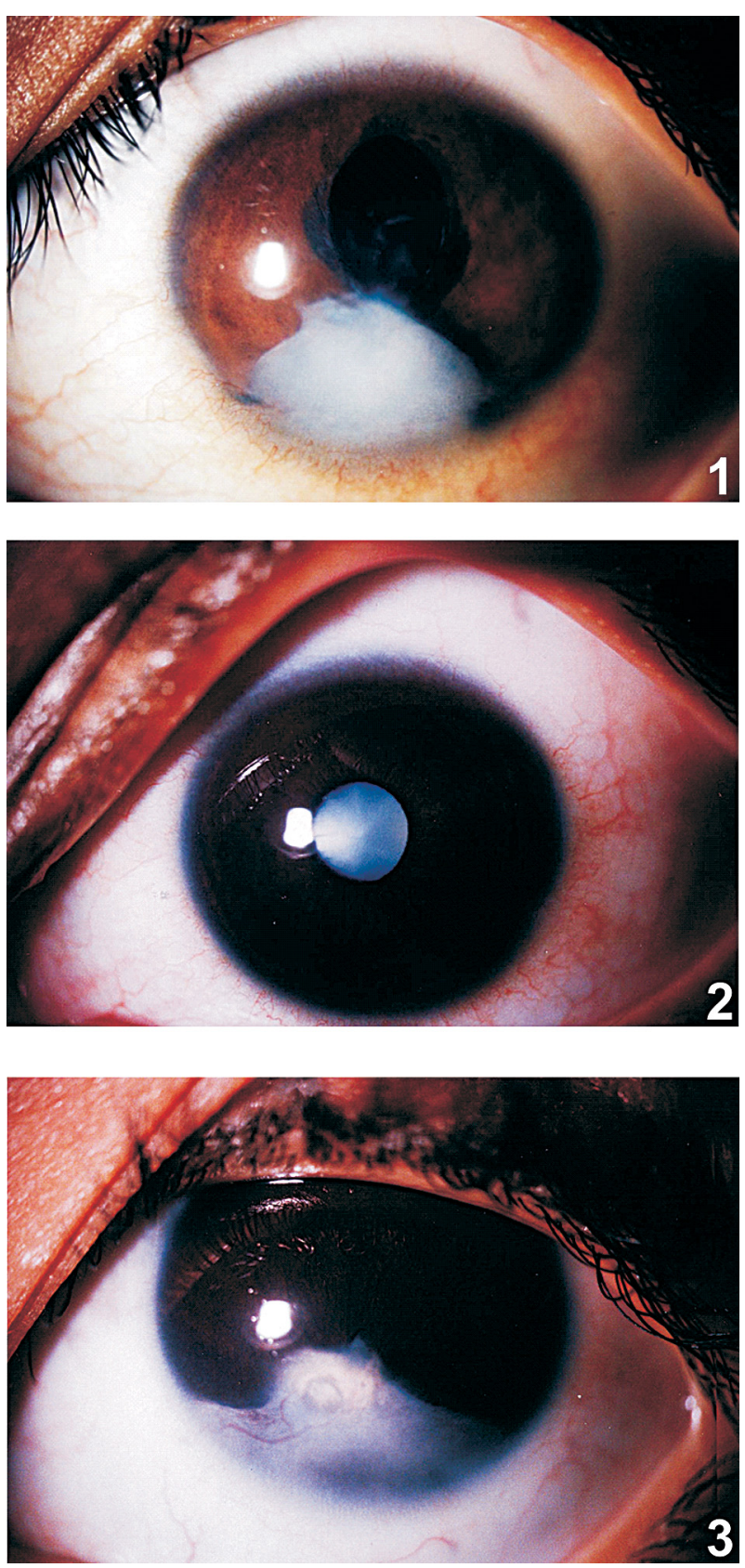

Fig. 1: photograph of the left eye of Case 1, with anterior chamber showing a white mass inferiorly. Fig. 2: photograph of the left eye of Case 2, showing total cataract. Fig. 3: photograph of the left eye of Case 3, disclosing a white vascularized mass in the anterior chamber. 
Case 3 - A 8-year-old boy (IVAA) displayed low vision in OS for six months. On July 5, 2005, BCVA was $20 / 20$ in OD and 20/100 in OS. Intraocular pressure was $11 \mathrm{mmHg}$ in OD and $5 \mathrm{mmHg}$ in OS. Anterior segment was normal in OD and abnormal in OS, with inferior adherent leukoma, deep vascularization and light cellularity in the anterior chamber $(1+/ 4+)$ (Fig. 3). Funduscopy was normal. He was treated with topical $1 \%$ tropicamide (q12h), $0.3 \%$ ciprofloxacin (q8h), and 1\% prednisolone acetate $(\mathrm{q} 8 \mathrm{~h})$ in OS. He presented worsening of vision and inflammatory reaction, receiving oral prednisone thereafter. Finally, he underwent cataract extraction with IOL implantation in OS. After surgery, he developed an inflammatory pupillary membrane; BCVA was counting fingers at 0.5 . A new surgery is to be programmed.

Histopathological study - The material of the three patients consisted of eosinophilic acellular and fragmented bands of lens cortex and vitreous, mixed with several minute scutelliform gemmoscleres of the freshwater sponges $D$. uruguayensis (the larger ones) and $D$. ctenosclera (Figs 4-7). The gemoscleres were weakly PAS positive and in confocal microscopy, using reflected mode, they present a concentric arrangement of fluorescent material (Figs 10-12). In the cases 1 and 2, the spicules were abundant (Figs 4-7, 10, 11) and few macrophages also appeared intermixed with the proteinaceous material. In the case 3 , proteinaceous globular material (Fig. 9), and filamentous structures (not shown) that may correspond to deuteromycetes (Penicillium or Aspergillus) were also seen. In this case, some crystalline fragments were impregnated with melanin. Sometimes, the degenerated crystalline material acquired a fibrillar arrangement. Peripheral vacuolization of the crystalline proteins displaying vacuoles of different sizes was easily differentiated from the sponje spicules (Fig. 8). The anterior lens capsule and the single layer of epithelial cells were not identified in the material.
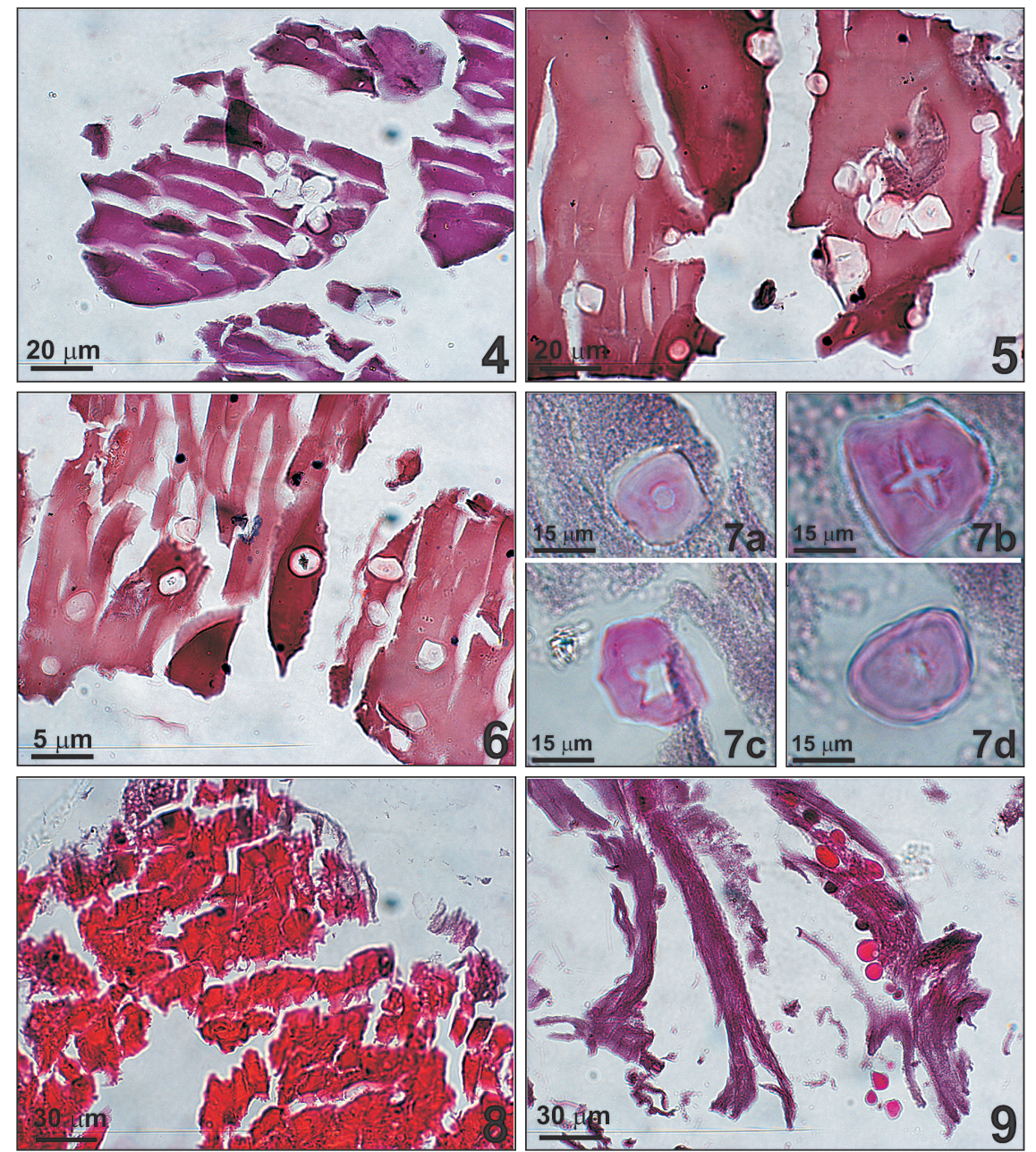

Figs 4-6: scutelliform gemmoscleres of freshwater sponge Drulia uruguayensis mixed with eosinophilic acellular and fragmented bands of lens cortex of two patients (4:HE; 5:Sirius red pH10.2; 6:PAS). Fig. 7: details of gemmoscleres of D. uruguayensis showing the following characteristics: central area (Fig. 7A), corresponding to hollow part of the spine shaft, which in the Figs 7B and $\mathrm{C}$ has a radial appearance. The gemmoscleres evince irregular contour and pronounced curved border (Figs 7B and D) (PAS). Fig. 8: peripheral vacuolization of the crystalline proteins displaying vacuoles of different sizes (HE). Fig. 9: intraocular filaments of proteinaceous material presenting eosinophilic globules (HE). 
Confocal analysis of purified material from the freswater sponges $D$. uruguayensis and D. ctenosclera, showed gemmoscleres with the same aspects observed in intraocular material (Figs 13-20).

\section{DISCUSSION}

This is the first time that freshwater sponge spicules are demonstrated to be ethiological agents of ocular injuries and they correspond to two of the sponge species detected by Volkmer-Ribeiro and Batista (pers. commun.) in the Araguaia waters at the site where the children were bathing and diving with open eyes.

The magnified photographs of purified gemmoscleres of D. uruguayensis and D. ctenosclera, dissociated from sponge fragments with gemmules (Figs 13-20), were used for comparison with the gemmoscleres found in the ocular tissues (Figs 4-7, 10-12). The confirmation of the species identification was also carried out upon comparison with the bibliography (Volkmer-Ribeiro \& Tavares 1995). The fact that the spicules were fluorescent, exhibiting a concentric arrangement of the fluorescent material (Fig. 12), suggests the incorporation of some type of protein(s) or glycoprotein(s) during their gradual formation starting from the central and radial axial channels.

The very sharp pointed spines of these types of gemmoscleres and its general shape of thumbtack (Figs $13-15,18-20)$ probably contribute to its adherence on the conjunctiva or cornea surfaces. The itching caused by the spicule contact with the ocular tissues may trigger initial penetration by mechanical scratching, followed by further epithelial ulceration, inducing deep subepithelial inflammatory reaction. The epithelial microulcerations, seen in other cases not included in this work, may facilitate the ingress of infectious or parasitic agents, as was verified in two cases of conjunctiva adiaspiromycosis (Mario Moraes, pers. commun.). It is important to point out that the freshwater sponge spicules are made of amorphous $\mathrm{SiO} 2$ that is opal, behaving as glass tiny bodies inserted into the ocular conjunctiva and/or cornea. Human skin injuries caused by freshwater sponge spicules at the Amazon have been recently described (Magalhães et al. 2005, 2006).

However, reports that the native Amazonian cultures were acquainted with procedures preventing ocular, gastric, and skin injuries, caused by river waters rich in sponges (cauxi, cauí) (Matta 1934, Machado 1947, Hilbert 1955), testimonies the risk offered by the spicules. Otherwise, waters rich in sponges are natural unpolluted waters. Removal of Porifera fauna would stand for a larger dispersion of their gemmules, promoting downstream colonization.

The mechanism of spicule transference from the surface to the anterior chamber was not yet detected and remains unknown, but is probably due to the inflammatory reaction. The authors set forth the hypothesis that
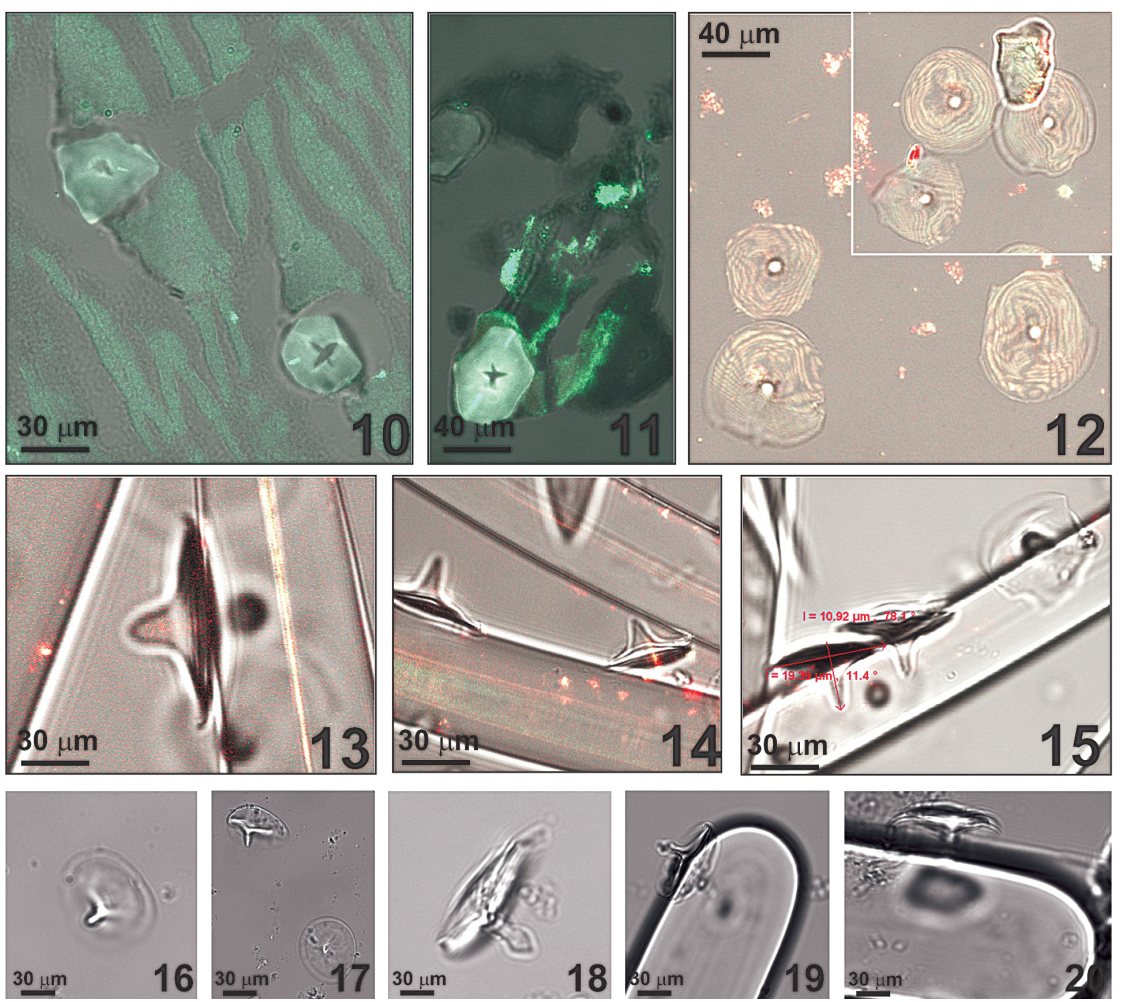

Figs 10,11: gemmoscleres of Drulia uruguayensis in intraocular material showing fluorescence in PAS. The radial aspect of the spine shaft is clearly seen (confocal microscopy). Figs 12-15: dissociated gemmoscleres of D. uruguayensis from Araguaia river. Fig. 12: concentric fluorescent banding pattern (emitted light in confocal microscopy). Figs 13-15: profile view of several gemmoscleres, leaning on the surface of megascleres, with the sharp ending of its central spine (transmitted light in confocal microscopy). Figs 16-20: minute, almost transparent, scutelliform, circular gemmoscleres of $D$. ctenosclera, some seen in profile (Figs 18-20) (transmitted light in confocal microscopy). 
the inflammatory reaction gradually extends far downward below epithelial surface, provoking, in the acute phase, deep conjunctiva microabcesses, that can unload to the subjacent anterior chamber. The structure of the gemmoscleres appears to favor this out-in transference, because megascleres and microscleres were not identified in the intraocular material of the presented patients. Dermircan et al. (2005) evaluated 70 cases of ocular injuries with intraocular foreign bodies and detected that the site of penetration was cornea in 58 $(82 \%)$, sclera in $8(11.4 \%)$, and limbus in $4(5.7 \%)$ eyes. The foreign body was in the vitreous in $40(57 \%)$ and embedded in the retina in $30(42.9 \%)$. An unusual case of orbital cellulites was reported in a cat, where the histopathology showed an intraocular foreign body of grass that had migrated through the sclera causing a suprachoroidal abcess with choroidal and retinal detachment (Tovar et al. 2005). An infrequent case of endophthalmitis due to intraocular caterpillar hairs was also described (Marti-Huguet et al. 1987). An intraretinal cilium was found in a young farmer with severe eye pain, scleritis and a circumscribed chorioretinal and vitreous infiltrate, without history or evidence of eye trauma or systemic disease (Wirth \& Helbig 2005). These varied cases indicate that the mechanism of intraocular foreign body penetration still deserves further studies.

The degree of ocular reactive changes secondary to foreign bodies depends mainly on the size, nature, and location of the particles and the length of time they are retained (Karcioglu 1985). Glass, noble metals, and many plastic compounds are fairly inert and often are well tolerated by the eye (Karcioglu 1985). But the spicules, although they are glass-like, they contain other proteins that can induce allergic and/or inflammatory reaction. Iron and copper are toxic and may produce ocular siderosis (Weiss et al. 1997) and chalcosis (Rao et al. 1976, Rosenthal et al. 1979), respectively. Intraocular vegetable fibers, which can easily be identified by polarizing microscopy, often are accompanied by extensive inflammation and foreign body reaction. Fungal infections commonly are associated with intraocular vegetable material (Karcioglu 1985).

This work alerts to the importance to analyze the quality of water where the people use to take bath, because outbreaks of conjunctival lesions have occurred in other places of the world (Rathinam et al. 2001).

The only recommended medical preventive attitude is to prohibit children from bathing and diving in such waters and this requires intense environment health education programs and awareness about the subject by the public administrators and by the community health services.

\section{ACKOWLEGMENTS}

To LFG Caputo, AM dos Anjos, LHP Barros, and LS Souza for technical assistance.

\section{REFERENCES}

Bogomoletz W 1980. Avantages de la coloration par le rouge Sirius de l'amyloïde et des éosinophiles. Arch Anat Cytol Pathol 28: 252-253.
Brazil TPS 1938. Cauicy. Relatório apresentado ao Ministério das Relações Exteriores em 1938 pelo chefe da Comissão Demarcadora de Limites do Sector de Oeste, Leuzinger S.A., Rio de Janeiro, 11-23 + 5 est.

Demircan N, Soylu M, Yagmur M, Akkaya H, Ozcan AA, Varinli I 2005. Pars plana vitrectomy in ocular injury with intraocular foreign body. J Trauma 59: 1216-1218.

Hilbert PP 1955. A cerâmica arqueológica de Oriximiná. Publicação do Instituto de Antropologia e Etnologia do Pará. Museu Goeldi 9: 33-337.

Karcioglu ZA 1985. Eye and ocular adnexa. In ZA Karcioglu, A Someren (eds), Practical Surgical Pathology, The Collamore Press, Lexington, p. 1045-1093.

Luque EH, Montes GS 1989. Progesterone promotes a massive infiltration of the rat uterine cervix by the eosinophilic polymorphonuclear leukocytes. Anat Rec 223: 257-265.

Machado OX de B 1947. Zoologia: Espongiários (Porifera), Imprensa Nacional, Rio de Janeiro.

Magalhães AO, Lemos APF, Cardoso JLC, Volkmer-Ribeiro C, Dos-Santos MC, Barcellos JFM 2005. Experimental dermatosis due to cauxi (Drulia uruguayensis Porifera). Mem Inst Butantan 62: 118.

Magalhães AO, Volkmer-Ribeiro C, Barcellos JFM, Cardoso JLC, Dos-Santos MC 2006. Report on two cases of human skin injuries caused by sponge spicules at Amazon. 7th International Sponge Symposim, Búzios, Rio de Janeiro. Book of Abstracts, p. 150.

Matta A da 1934. Cai e Cauxí. Rev Inst Hist Geog do Amazonas 4: 129-132.

Marti-Huguet T, Pujol O, Cabiro I, Oteyza JA, Roca G, Marsal J 1987. Endophthalmos caused by intravitreal caterpillar hairs. Treatment by direct photocoagulation with argon laser. $J \mathrm{Fr}$ Ophtalmol 10: 559-564.

Rao NA, Tso MO, Rosenthal AR 1976. Chalcosis in the human eye. A clinicopathological study. Arch Ophthalmol 94: 13791384.

Rathinam S, Fritsche TR, Srinivasan M, Vijayalakshmi P, Read R, Gautom R, Namperumalsamy P, Narsing AR 2001. An outbreak of trematode-induced granulomas of the conjunctiva. Ophthalmology 108: 1223-1229.

Rosenthal AR, Marmor MF, Leuenberger P, Hopkins JL 1979. Chalcosis: a study of natural history. Ophthalmology 86 : 1956-1972.

Tovar MC, Huguet E, Gomezi MA 2005. Orbital cellulitis and intraocular abcess cause by migrating grass in a cat. Vet Ophthalmol 8: 353-356.

Volkmer-Ribeiro C, Tavares MCM 1995. Redescrição de Drulia uruguayensis Bonetto \& Ezcurra de Drago, 1968 com redefinição do gênero Drulia Gray, 1867 (Porifera: Metaniidae). Biociências 3: 183-205.

Weiss MJ, Hofeldt AJ, Behrens M, Fisher K 1997. Ocular siderosis. Diagnosis and management. Retina 17: 105-108.

Wirth MG, Helbig H 2005. Can eyelashes migrate? Klin Monatsbl Augenheilkd 222: 238-240. 